\title{
CD40 polymorphisms were associated with HCV infection susceptibility among Chinese population
}

Ting Tian ${ }^{1,2 \dagger}$, Peng Huang ${ }^{1 \dagger}$, Jingjing $\mathrm{Wu}^{1}$, Chunhui Wang ${ }^{3}$, Haozhi Fan ${ }^{1}$, Yun Zhang ${ }^{1}$, Rongbin $\mathrm{Yu}^{1}$, Chao Wu ${ }^{4}$, Xueshan $\mathrm{Xia}^{5}$, Zuqiang $\mathrm{Fu}^{1}$, Jun $\mathrm{Li}^{6}$ and Ming Yue

\begin{abstract}
Background: CD40, encoded by TNFRSF5, participates in the survival of B cells, process of antigen presentation and generation of CD8+ T cell memory. It also has an important effect on HCV antiviral immune response. This study aims to investigate whether TNFRSF5 gene polymorphisms are associated with HCV infection outcomes among Chinese population.

Methods: Three single nucleotide polymorphism (SNPs) (rs1535045, rs1883832, rs4810485) on TNFRSF5 were genotyped by TaqMan assay among Chinese population, including 1513 uninfected subjects, 496 spontaneous viral clearance subjects and 768 persistent HCV-infected subjects. Logistic analysis was used to compare these SNPs among different groups in this cross-sectional study. Functional annotations of the identified SNPs were further evaluated by bioinformatics analysis.

Results: After adjusted by age, gender and routes of infection, the results of logistic analysis indicated that individuals carrying rs1535045 T allele had a higher risk to infect HCV compared with C allele (in recessive model, adjusted $\mathrm{OR}=1.368,95 \% \mathrm{Cl}=1.070-1.749, P=0.012$ ). Subjects carried $\mathrm{rs} 1535045 \Pi$ genotype were more likely to infect HCV than wild CC genotype (adjusted $\mathrm{OR}=1.397,95 \% \mathrm{Cl}=1.078-1.809, P=0.011$ ). For rs 1883832, T allele was significantly associated with an increased risk of $\mathrm{HCV}$ infection (in recessive model, adjusted $\mathrm{OR}=1.337,95 \% \mathrm{Cl}=$ 1.069-1.673, $P=0.011$ ). Subjects with $\Pi$ genotype had more possibility to infect $\mathrm{HCV}$ (adjusted $\mathrm{OR}=1.351,95 \% \mathrm{Cl}=$ 1.060-1.702, $P=0.015$ ). In the stratified analysis, rs 1535045 and rs 1883832 were remained in various subgroups and the heterogeneity test showed no pronounced heterogeneity in any pairwise comparison (all $P>0.05$ ). In addition, the results of the cumulative effects showed a tendency of that the more risk alleles (rs1535045 T and rs1883832 T) subjects carried, the more possibility of HCV infection exhibited $(P<0.001)$. In haplotype analyses, compared with the CC haplotype, CT, TC and TT was correlated with an increased risk to infect HCV $(P=0.029, P=0.047$ and $P<0.001$, respectively).
\end{abstract}

Conclusions: In conclusion, CD40 polymorphisms were significantly associated with the susceptibility to HCV among Chinese populations.

Keywords: Hepatitis C virus, CD 40, Genetic polymorphism, Susceptibility, Infection outcomes

\footnotetext{
* Correspondence: njym08@163.com

†Ting Tian and Peng Huang contributed equally to this work.

${ }^{6}$ Department of Infectious Diseases, the First Affiliated Hospital of Nanjing

Medical University, No. 300 Guangzhou Road, Nanjing 210029, Jiangsu, China

Full list of author information is available at the end of the article
}

(c) The Author(s). 2019 Open Access This article is distributed under the terms of the Creative Commons Attribution 4.0 International License (http://creativecommons.org/licenses/by/4.0/), which permits unrestricted use, distribution, and reproduction in any medium, provided you give appropriate credit to the original author(s) and the source, provide a link to the Creative Commons license, and indicate if changes were made. The Creative Commons Public Domain Dedication waiver (http://creativecommons.org/publicdomain/zero/1.0/) applies to the data made available in this article, unless otherwise stated. 


\section{Background}

It is estimated that more than 184 million people around the world are infected with hepatitis $\mathrm{C}$ virus (HCV). $\mathrm{HCV}$ infection has brought about large burden on many countries resulting from the highly correlated hepatic and extrahepatic disorders such as cirrhosis, hepatocellular carcinoma and hepatic failure [1]. Furthermore, current vaccines are not available for effective prevention of HCV infection [2].

As is known, host genetic factors play an important role in infection outcome of $\mathrm{HCV}$ and the response to antiviral therapies [3]. IL-28B rs12979860 and HLA class II rs4273729 are independently associated with spontaneous resolution of HCV infection [4]. Genome-wide association studies (GWASs) of patients with chronic hepatitis $\mathrm{C}$ have identified the association between IL28B variations, especially rs12979860 and rs8099917, and response to treatment with peg-interferon alpha and ribavirin $[5,6]$. Therefore, it is still essential to figure out the atlas of disease related genetic factors.

CD40, also known as tumor necrosis factor receptor superfamily 5 (TNFRSF5), which is principally expressed on the B cells, participates in the survival of B cells, process of antigen presentation and generation of $\mathrm{CD} 8+\mathrm{T}$ cell memory [7]. It also has an important effect on antiviral immune response. In HCV-associated chronic liver diseases, CD40 is highly expressed on liver tissues and has a key role in hepatocyte survival [8]. To be more specific, CD40 can inhibit $\mathrm{HCV}$ replication and mediate viral clearance, and disruptions by activated innate immune mechanism [9]. CD40 gene polymorphisms have been found to be associated with many immune related disorders, for instance, Kawasaki Disease, systemic lupus erythematosus and lung cancer [10-12]. According to previous study, rs1535045 $\mathrm{T}$ allele was higher than $\mathrm{C}$ allele in Coronary Artery Disease (CAD) patients [12]. It also has been found that rs1883832 T allele was associated with higher risk of sepsis [13]. One metaanalysis showed a significant association between the CD40 rs4810485 $\mathrm{T}$ allele and rheumatoid arthritis (RA) [14] However, so far, no relevant research has addressed the association between $C D 40$ genetic variants and HCV infection susceptibility or outcomes. Hence, this study aimed to explore the relationships between $C D 40$ genetic variants and $\mathrm{HCV}$ infection outcomes among a Chinese high-risk population, including rs1535045, rs1883832 and rs4810485.

\section{Methods}

\section{Study subjects}

This study incorporates three high risk populations up to 2777 subjects. We recruited 720 hemodialysis (HD) subjects from nine hospital hemodialysis centers from October 2008 to May 2015, 459 intravenous drug users recruited from Nanjing compulsory detoxification center from December 2008 to November 2012 and 1598 paid blood donors from six villages in Zhenjiang City from October 2008 to September 2016. Exclusion criteria are as follows: 1. concurrently infected with other virus (human immunodeficiency virus or hepatitis B virus); 2. suffered from any other liver diseases (e.g. alcoholic, autoimmune or metabolic liver diseases); 3. accepted any antiviral therapies during this whole study. All participants were categorized into three groups. Group A were health subjects who were tested both anti-HCV and HCV-RNA negative. Group B were the spontaneous clearance group who were tested anti-HCV positive and HCV-RNA negative. Group $\mathrm{C}$ were called persistent infection group whose anti-HCV and HCV RNA were both seropositive. It is worth noting that all serological results were verified by three independent experiments within six consecutive months.

Demographic data, dangerous behavior exposure and medical histories of $\mathrm{HCV}$ infection were collected through structured questionnaires designed by professionals. Only achieved the rigorous professional trainings could the investigators carry out the interview for each participant. Quality control was throughout the entire process of investigation in order to make sure that the collected data was true and reliable.

\section{Viral testing}

After the interview, an approximately 10-mL morning fasting venous blood was collected from each participant. The serum and white blood cells were isolated at the speed of $4000 \mathrm{rpm}$ for $10 \mathrm{~min}$ immediately and refrigerate at $-80{ }^{\circ} \mathrm{C}$ before using. Taking appropriate approaches for detection of anti-HCV antibodies, HCVRNA and diverse HCV genotypes followed by the standard operating protocols. The reagents used for each step were the third-generation enzyme-linked immunosorbent assay (for anti-HCV antibody), Trizol LS Reagent (for HCV-RNA) and Murex HCV Serotyping 1-6 Assay ELISA kit (for HCV genotype).

\section{SNPs selection and genotyping}

SNP searching strategies: 1) Candidate TNFRSF5 tagSNPs were download on the 1000 Genomes Project SNP database (www.internationalgenome.org) and selected through Haploview 4.2 software, 2) Potential functional SNPs predicted by following databases (UCSC, HaploReg v4.1, GTEx Portal, SNP Function Prediction, and microRNA-related SNP), 3) Relevant SNPs discovered by others scholars associated with viral hepatitis or other liver and immune-related disorders, 4) According to the criteria, the minor allele frequency (MAF) 
of selected SNPs must be more than 5\% among Chinese Han population. Finally, three SNPs (rs1535045, rs1883832 and rs4810485) were chosen into this study.

Genomic DNA of each subject was extracted from peripheral blood leukocytes by proteinase $\mathrm{K}$ and phenolchloroform respectively, and further purified by ethanol precipitation. We used TaqMan allelic discrimination assay to genotype three SNPs on an ABI PRISM 7900HT Sequence Detection System (Applied Biosystems, Foster City, CA, USA). For quality control, two blank controls were set in each 384-well plate, and a $100 \%$ concordance was achieved in $10 \%$ random samples. The success rates of genotyping for selected SNPs were all above 95\%. The samples failed for genotyping were excluded from the statistical analyses. The genotyping results were read by SDS 2.3 software (Applied Biosystems, Foster City, CA, USA). The primers and probes sequences for those SNPs were listed in Additional file 1: Table S1.

\section{Relevant public database}

The genotype information of TNFRSF5 in CHB population was downloaded from the 1000 Genomes Project Phase3 SNP database (www.internationalgenome.org). We have attempted to find expression quantitative trait loci (eQTL) evidence of positive loci based on the public GTEx Portal V6p database (http://www.gtexportal.org/). SNP functional annotations were performed on the HaploReg v4.1 database (http://archive.broadinstitute.org/ mammals/haploreg/haploreg.php), SNP Function Prediction (https://snpinfo.niehs.nih.gov/snpinfo/snpfunc.html) and UCSC genome browser (https://genome.ucsc.edu/ cgi-bin/hgGateway).

\section{Statistical analysis}

For further susceptibility analysis, Group B and Group C were combined as $\mathrm{HCV}$ infected group, then compared with Group A which are health subjects. For HCV chronicity analysis, Group C was contrasted with Group B. Differences of the distribution in demographic and clinical characteristics were compared between subjects among three groups. Wherever appropriate, these differences were evaluated using Student's $t$ test, $\mathrm{X}^{2}$-test, Kruskal-Wallis test or one-way analysis of variance. A goodness of fit $\chi^{2}$ test was used to test Hardy-Weinberg equilibrium (HWE) for each SNP among healthy subjects. Linkage disequilibrium (LD) parameters $\left(\mathrm{r}^{2}\right.$ and $\mathrm{D}$ ') of selected SNPs in CHB population were estimated by Haploview software (version 4.2). The odds ratios and 95\% confidence intervals were used to estimate the association between SNPs and the HCV infection outcomes by adjusting age, gender and routes of infection using both univariate and multivariate logistic regression models in this cross-sectional study. $P<0.05$ in a two- sided test was considered statistically significant. Bonferroni correction was used to conduct multiple comparisons among genotypes and the $P$ value was adjusted to $0.0167(0.05 / 3)$. All the analyses were carried out by Stata/SE (V.12.0 for Windows; StataCorp LP, College Station, TX, USA).

\section{Results \\ General demographic information}

Demographical and clinical characteristics of all subjects were listed in Table 1. The distribution of age and gender were balanced among Group A, Group B and Group $C$ (all $P>0.05$ ), while the ALT, AST and routes of infection were significantly different among three groups (all $P<0.001)$. HCV genotypes of partial $\mathrm{HCV}$ patients were statistically different between Group B and Group $\mathrm{C}(\mathrm{P}<$ 0.05). The three SNPs were all in accordance with Hardy-Weinberg equilibrium in the Group A $(P=0.553$ for rs1535045, $P=0.130$ for $\mathrm{rs} 1883832$ and $P=0.723$ for rs4810485).

\section{Association between polymorphisms in CD40 gene and susceptibility to HCV infection}

The distributions of rs1535045, rs1883832, and rs4810485 genotypes among Group A, Group B, and Group $\mathrm{C}$ were shown in Table 2. To explore the association between $C D 40$ polymorphisms and hepatitis $C$ susceptibility, logistic regression methods were used by constructing three genetic models (additive, dominant and recessive). After adjusted by age, gender and routes of infection, the logistic regression analysis discovered that rs1535045 $\mathrm{T}$ allele was remarkably bound up with higher risk to infect $\mathrm{HCV}$ compared with $\mathrm{C}$ allele (in recessive model, adjusted $\mathrm{OR}=1.368,95 \% \mathrm{CI}=1.070$ $1.749, P=0.012)$. Subjects carried rs1535045 TT genotype were more likely to infect $\mathrm{HCV}$ than wild $\mathrm{CC}$ genotype (adjusted $\mathrm{OR}=1.397,95 \% \mathrm{CI}=1.078-1.809, P=$ 0.011 ). For rs 1883832 , $\mathrm{T}$ allele was significantly associated with an increased risk of $\mathrm{HCV}$ infection (in recessive model, adjusted $\mathrm{OR}=1.337,95 \% \mathrm{CI}=1.069-1.673$, $P=0.011)$. Subjects with TT genotype had higher possibility to infect $\mathrm{HCV}$ (adjusted $\mathrm{OR}=1.351,95 \% \mathrm{CI}=$ 1.060-1.702, $P=0.015)$.

\section{Association of $C D 40$ polymorphisms with the spontaneous clearance of HCV infection}

When exploring the association of TNRSF5 polymorphisms with the spontaneous clearance of $\mathrm{HCV}$ infection, we proceeded association study by comparing the distribution of genotypes of selected SNPs in the persistent infection group and spontaneous clearance group after the adjustment by gender, age and routes of infection. No significant association was discovered in any of the three SNPs (rs1535045, rs1883832 and rs4810485) 
Table 1 Demographical and clinical characteristics among HCV control, spontaneous clearance and persistent infection populations

\begin{tabular}{|c|c|c|c|c|}
\hline \multirow[t]{2}{*}{ Variables } & Group A (\%) & Group B (\%) & Group C (\%) & \multirow[t]{2}{*}{$P$} \\
\hline & $n=1513$ & $n=496$ & $n=768$ & \\
\hline Age (years, mean $\pm S D$ ) & $52.65 \pm 13.30$ & $51.12 \pm 13.82$ & $51.89 \pm 12.37$ & $0.076^{\mathrm{a}}$ \\
\hline Gender & & & & $0.130^{b}$ \\
\hline Male & $603(39.9)$ & $194(39.1)$ & $273(35.5)$ & \\
\hline Female & $910(60.1)$ & $302(60.9)$ & $495(65.5)$ & \\
\hline $\operatorname{ALT}(\mathrm{U} / \mathrm{L})$ & & & & $<0.001^{\mathrm{b}}$ \\
\hline$<40$ & $1421(94.9)$ & $387(78.2)$ & $443(57.8)$ & \\
\hline$\geq 40$ & $77(5.1)$ & $108(21.8)$ & $323(42.2)$ & \\
\hline \multicolumn{5}{|l|}{ AST (U/L) } \\
\hline$<40$ & $1422(95.1)$ & $394(80.9)$ & $454(60.0)$ & $<0.001^{b}$ \\
\hline$\geq 40$ & $74(4.9)$ & $93(19.1)$ & $303(40.0)$ & \\
\hline Route of infection & & & & $<0.001^{\mathrm{b}}$ \\
\hline $\mathrm{HD}$ & $553(36.5)$ & $91(18.3)$ & $76(9.9)$ & \\
\hline IVDU & $181(12.0)$ & $138(27.8)$ & $140(18.2)$ & \\
\hline PBD & 779 (51.5) & $267(53.9)$ & $552(71.9)$ & \\
\hline HCV genotypes & & & & $<0.001^{\mathrm{b}}$ \\
\hline $1 b$ & - & $42(26.3)$ & $223(46.1)$ & \\
\hline Non-1b & - & $118(73.7)$ & $261(53.9)$ & \\
\hline
\end{tabular}

Abbreviations: ALT alanine transaminase, AST aspartate aminotransferase, $H C V$ hepatitis $C$ virus, $H D$ hemodialysis, IVDU Intravenous drug user, PBD paid blood donors

Group A: controls; Group B: spontaneous clearance subjects; Group C: persistent infection patients

${ }^{a} P$ value of one-way ANOVA among three groups

${ }^{b} P$ value of $X^{2}$-test among three/two groups

with the virus spontaneous clearance both in the additive, dominant, recessive models (all $P>0.05$, Table 2).

\section{Stratified analysis}

Considering that the genetic pattern of positive SNPs is recessive, we conducted the stratification analysis in recessive model (Table 3). We found that the rs1535045 were significant in female (adjusted $\mathrm{OR}=1.639,95 \% \mathrm{CI}=$ 1.181-1.274, $P=0.003$ ) and paid blood donors (adjusted $\mathrm{OR}=1.417,95 \% \mathrm{CI}=1.013-1.985, P=0.042)$ subgroups after adjusted by age, gender and routes of infection. As for rs1883832, it remained meaningful in young (adjusted $\mathrm{OR}=1.485,95 \% \mathrm{CI}=1.020-2.162, P=0.039$ ), male (adjusted $\mathrm{OR}=1.532,95 \% \mathrm{CI}=1.077-2.180, \quad P=0.018$ ), hemodialysis patients (adjusted $\mathrm{OR}=2.042,95 \% \mathrm{CI}=$ 1.225-3.404, $P=0.006$ ) and paid blood donors (adjusted $\mathrm{OR}=1.836,95 \% \mathrm{CI}=1.021-3.304, P=0.043)$ subgroups. The heterogeneity test showed no pronounced heterogeneity in any pairwise comparison $(P>0.05)$.

\section{Cumulative effects of rs1535045 and rs1883832 on the susceptibility of HCV infection}

The analysis of combined risk alleles (rs1535045 T allele and rs1883832 $\mathrm{T}$ allele) came to conclusions that subjects carried three risk alleles or four risk alleles were more likely to be infected when compared with subjects carried no risk alleles (adjusted $\mathrm{OR}=1.947$, $95 \% \mathrm{CI}=1.741-2.179, P<0.001$, Table 4). Nevertheless, those carried one and two risk alleles showed no higher possibility to infect $\mathrm{HCV}$ than subjects who carried risk-free alleles. These two SNPs had trend influence on more possibility of being infected by $\mathrm{HCV}$ after the Cochran-Armitage trend test $(P<0.001)$.

\section{Haplotype analysis}

According to the information from Haploview software (version 4.2), the rs1535045 (C/T) and $\mathrm{rs} 1883832(\mathrm{C} / \mathrm{T})$ were strongly linkage disequilibrium $\left(D^{\prime}=1.000, r^{2}=\right.$ 0.283). As these two SNPs were both associated with increased risk of $\mathrm{HCV}$ infection, we evaluated the combined effects of these two SNPs on HCV susceptibility by haplotype analysis. As shown in Table 5, compared with most frequent CC haplotype, subjects carrying haplotype CT (adjusted $\mathrm{OR}=1.161,95 \% \mathrm{CI}=1.015-1.327, P=0.029)$, TC (adjusted OR $=1.151,95 \% \mathrm{CI}=1.002-1.323, P=0.047$ ) and TT (adjusted OR $=2.550,95 \% \mathrm{CI}=1.665-3.905, P<0.001$ ) were more likely to infect $\mathrm{HCV}$. 
Table 2 Genotypes distributions of TNFRSF5 SNPs among control, spontaneous clearance and persistent infection groups

\begin{tabular}{|c|c|c|c|c|c|c|c|}
\hline \multirow[t]{2}{*}{ SNPs (genotype) } & \multirow{2}{*}{$\begin{array}{l}\text { Group A } \\
\mathrm{n}(\%)\end{array}$} & \multirow{2}{*}{$\begin{array}{l}\text { Group B } \\
\mathrm{n}(\%)\end{array}$} & \multirow{2}{*}{$\begin{array}{l}\text { Group C } \\
\mathrm{n}(\%)\end{array}$} & \multicolumn{2}{|l|}{ Group $(B+C) /$ Group $A$} & \multicolumn{2}{|l|}{ Group C/Group B } \\
\hline & & & & $\mathrm{OR}(95 \% \mathrm{Cl})^{\mathrm{a}}$ & $p^{a}$ & $\mathrm{OR}(95 \% \mathrm{Cl})^{\mathrm{b}}$ & $p^{b}$ \\
\hline \multicolumn{8}{|l|}{ rs1535045 } \\
\hline CC & $688(46.5)$ & $214(43.9)$ & $328(43.6)$ & 1.00 & - & 1.00 & - \\
\hline $\mathrm{CT}$ & $648(43.8)$ & $211(43.3)$ & $322(42.8)$ & $1.043(0.884-1.231)$ & 0.618 & $0.979(0.763-1.256)$ & 0.867 \\
\hline$\pi$ & $142(9.7)$ & $62(12.8)$ & 103 (13.6) & $1.397(1.078-1.809)$ & 0.011 & $1.095(0.760-1.576)$ & 0.626 \\
\hline Dominant model & & & & 1.109 (0.948-1.297) & 0.197 & $1.005(0.796-1.271)$ & 0.964 \\
\hline Additive model & & & & $1.135(1.011-1.275)$ & 0.032 & $1.027(0.869-1.215)$ & 0.752 \\
\hline Recessive model & & & & $1.368(1.070-1.749)$ & 0.012 & $1.106(0.785-1.559)$ & 0.564 \\
\hline \multicolumn{8}{|l|}{ rs1883832 } \\
\hline CC & $567(39.4)$ & $178(37.3)$ & $275(37.7)$ & 1.00 & - & 1.00 & - \\
\hline $\mathrm{CT}$ & $693(48.2)$ & $217(45.5)$ & $333(45.6)$ & $1.019(0.858-1.210)$ & 0.833 & $1.008(0.778-1.306)$ & 0.951 \\
\hline$\pi$ & $178(12.4)$ & $82(17.2)$ & $122(16.7)$ & $1.351(1.060-1.722)$ & 0.015 & $0.980(0.695-1.383)$ & 0.909 \\
\hline Dominant model & & & & $1.090(0.926-1.282)$ & 0.300 & $1.001(0.785-1.275)$ & 0.997 \\
\hline Additive model & & & & $1.127(1.004-1.263)$ & 0.042 & $0.993(0.841-1.173)$ & 0.937 \\
\hline Recessive model & & & & $1.337(1.069-1.673)$ & 0.011 & $0.976(0.713-1.335)$ & 0.878 \\
\hline \multicolumn{8}{|l|}{ rs4810485 } \\
\hline GG & 604 (40.6) & $190(39.7)$ & $306(41.0)$ & 1.00 & - & 1.00 & - \\
\hline GT & $693(46.6)$ & $211(44.1)$ & $328(43.9)$ & $0.970(0.819-1.148)$ & 0.721 & $0.981(0.761-1.266)$ & 0.885 \\
\hline$\pi$ & $191(12.8)$ & $78(16.2)$ & $113(15.1)$ & $1.201(0.944-1.527)$ & 0.136 & $0.927(0.655-1.312)$ & 0.667 \\
\hline Dominant model & & & & $1.021(0.871-1.196)$ & 0.802 & $0.967(0.762-1.227)$ & 0.780 \\
\hline Additive model & & & & 1.063 (0.949-1.190) & 0.290 & 0.967 (0.819-1.141) & 0.688 \\
\hline Recessive model & & & & $1.220(0.976-1.526)$ & 0.081 & $0.936(0.679-1.290)$ & 0.685 \\
\hline
\end{tabular}

Abbreviations: $\mathrm{Cl}$ confidence interval, $H C V$ hepatitis $\mathrm{C}$ virus, $O R$ odds ratio, SNP single nucleotide polymorphism

Group A: controls; Group B: spontaneous clearance subjects; Group C: persistent infection patients. Group $(B+C)$ : Infected individuals

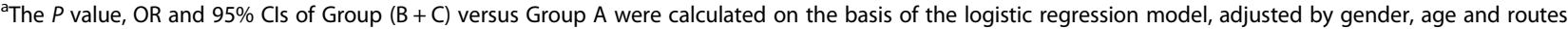

of infection

${ }^{\mathrm{b}}$ The $P$ value, OR and $95 \% \mathrm{Cls}$ of Group C versus Group B were calculated on the basis of the logistic regression model, adjusted by gender, age and routes of infection

Bonferroni correction was applied and the $P$ value was adjusted to $0.0167(0.05 / 3)$

Bold type indicates statistically significant results

\section{Discussion}

Up to now, the pathogenesis of HCV has not been illuminated clearly enough because a number of immunerelated pathways and a series of genes involve in the process of $\mathrm{HCV}$ infection. Growing researches on $\mathrm{HCV}$ are paid attention to find more genetic variations in order to identify relevant biological markers of the disease. We explored the possible associations between three CD40 SNPs (rs1535045, rs1883832 and rs4810485) and $\mathrm{HCV}$ infection outcomes. In this study, we found that genetic variants of $C D 40$ (rs1535045 $\mathrm{T}$ allele and rs1883832 $\mathrm{T}$ allele) were significantly associated with an increased risk of $\mathrm{HCV}$ infection among Chinese population at the fist time.

TNFRSF5 encodes a costimulatory protein called CD40, which have been found on antigen presenting cells. The CD40 has been found to play an essential role in mediating a broad variety of immune and inflammatory responses including $\mathrm{T}$ cell-dependent immunoglobulin class switching, memory B cell development, and germinal center formation [7, 15]. Various cytokines can control the expression level of CD40, particularly the IFN- $\gamma$, IL- $1 \beta$, and TNF- $\alpha$ enhancing the expression on monocytes [16], endothelial cells $[17,18]$, thymic epithelium [19] and in six HCC cell lines [20]. In HCV-associated chronic liver diseases, CD40 might have important effects on hepatocyte survival and death in $\mathrm{HCV}$-associated chronic liver diseases [8]. Studies demonstrated that CD40 signal can activate NF- $\kappa \mathrm{B}$ in a dose-dependent manner, then NF-kB inhibits Fas or Tumor Necrosis Factor Receptor (TNFR) mediated apoptosis by blocking the activation of caspase- $8[21,22]$. Specifically, CD 40 is up-regulated on hepatocytes during infection with 
Table 3 Stratified analysis of rs1535045 and rs1883832 among control, spontaneous clearance and persistent infection groups

\begin{tabular}{|c|c|c|c|c|c|}
\hline \multirow[t]{2}{*}{ SNPs } & \multirow[t]{2}{*}{ Allele } & \multirow[t]{2}{*}{ Subgroups } & \multicolumn{3}{|l|}{ Group $(B+C) /$ Group $A$} \\
\hline & & & $\mathrm{OR}(95 \% \mathrm{Cl})^{\mathrm{a}}$ & $P^{a}$ & $p^{b}$ \\
\hline \multirow[t]{10}{*}{ rs1535045 } & \multirow[t]{10}{*}{$C / T$} & \multicolumn{4}{|l|}{ Age } \\
\hline & & $<50$ & $1.417(0.973-2.064)$ & 0.069 & 0.787 \\
\hline & & $\geq 50$ & $1.323(0.955-1.832)$ & 0.092 & \\
\hline & & \multicolumn{4}{|l|}{ Gender } \\
\hline & & male & $1.240(0.764-1.652)$ & 0.551 & 0.158 \\
\hline & & female & $1.639(1.181-1.274)$ & 0.003 & \\
\hline & & \multicolumn{4}{|c|}{ Routes of infection } \\
\hline & & $H D$ & $1.285(0.684-2.413)$ & 0.436 & 0.479 \\
\hline & & Drug user & $0.985(0.607-1.598)$ & 0.951 & \\
\hline & & PBD & $1.418(1.013-1.985)$ & 0.042 & \\
\hline \multirow[t]{10}{*}{ rs1883832 } & \multirow[t]{10}{*}{$C / T$} & \multicolumn{4}{|l|}{ Age } \\
\hline & & $<50$ & $1.485(1.020-2.162)$ & 0.039 & 0.572 \\
\hline & & $\geq 50$ & 1.297 (0.979-1.719) & 0.070 & \\
\hline & & \multicolumn{4}{|l|}{ Gender } \\
\hline & & male & $1.532(1.077-2.180)$ & 0.018 & 0.344 \\
\hline & & female & $1.228(0.917-1.646)$ & 0.168 & \\
\hline & & \multicolumn{4}{|c|}{ Routes of infection } \\
\hline & & $\mathrm{HD}$ & $2.042(1.225-3.404)$ & 0.006 & 0.066 \\
\hline & & Drug user & $1.836(1.021-3.304)$ & 0.043 & \\
\hline & & PBD & $1.111(0.839-1.471)$ & 0.168 & \\
\hline
\end{tabular}

Abbreviations: $\mathrm{Cl}$ confidence interval, $H D$ hemodialysis, $P B D$ paid blood donors, $O R$ odds ratio

Group A: controls; Group B: spontaneous clearance subjects; Group C: persistent infection patients. Group (B $+\mathrm{C})$ : $\mathrm{HCV}$-infected individuals

${ }^{a}$ The $P$ value, $\mathrm{OR}$ and $95 \% \mathrm{Cls}$ of group $(\mathrm{B}+\mathrm{C})$ versus Group $\mathrm{A}$ were calculated on the basis of the binary logistic regression model, adjusted by gender, age and routes of infection in recessive model (TT versus [TC $+C C]$ )

${ }^{\mathrm{b}}$ The $P$ value for the heterogeneity test

Bold type indicates statistically significant results

Table 4 Cumulative effects of combined risk alleles (rs1535045 T and rs1883832 T) on the susceptibility to HCV infection

\begin{tabular}{lllll}
\hline Variables & Group A & Group B+ Group C & \multicolumn{3}{l}{ Group $(\mathrm{B}+\mathrm{C}) /$ Group A } \\
\cline { 5 - 5 } & $\mathrm{n}$ & $\mathrm{n}$ & $\mathrm{OR}(95 \% \mathrm{Cl})^{\mathrm{a}}$ & $P^{\mathrm{a}}$ \\
\hline 0 & 154 & 123 & 1 & \\
1 & 619 & 444 & $0.965(0.734-1.269)$ & 0.799 \\
2 & 615 & 550 & $1.179(0.899-1.546)$ & 0.233 \\
34 & 29 & 64 & $\mathbf{1 . 9 4 7}(\mathbf{1 . 7 4 1 - 2 . 1 7 9 )}$ & $<\mathbf{0 . 0 0 1}$ \\
Trend & & & & $<\mathbf{0 . 0 0 1} \mathbf{1}^{\text {b }}$ \\
0 & 154 & 123 & 1 & \\
$1-4$ & 1362 & 1138 & $1.114(0.862-1.440)$ & 0.411 \\
\hline
\end{tabular}

Abbreviations: HCV hepatitis C virus, OR odds ratio,95\% Cl 95\% confidence interval

Group A: controls; Group B: spontaneous clearance subjects; Group C: persistent infection patients. Group $(B+C)$ : $\mathrm{HCV}$-infected individuals

a Logistic regression model, adjusted for gender, age, and routes of infection

${ }^{\mathrm{b}}$ Cochran-Armitage trend test

Bold type indicates statistically significant results
Table 5 Haplotype analysis of rs1535045 and rs1883832 in the study population

\begin{tabular}{|c|c|c|c|c|}
\hline \multirow[t]{2}{*}{ Variables } & \multirow{2}{*}{$\begin{array}{l}\text { Group A } \\
n\end{array}$} & \multirow{2}{*}{$\begin{array}{l}\text { Group B+ Group C } \\
n\end{array}$} & \multicolumn{2}{|l|}{ Group $(B+C) /$ Group $A$} \\
\hline & & & $\overline{\mathrm{OR}(95 \% \mathrm{Cl})^{\mathrm{a}}}$ & $P^{a}$ \\
\hline CC & 985 & 728 & 1 & \\
\hline$C T$ & 1087 & 929 & $1.161(1.015-1.327)$ & 0.029 \\
\hline TC & 927 & 789 & $1.151(1.002-1.323)$ & 0.047 \\
\hline$\pi T$ & 33 & 76 & $2.550(1.665-3.905)$ & $<0.001$ \\
\hline
\end{tabular}

Abbreviations: $\mathrm{HCV}$ hepatitis C virus, OR odds ratio, $95 \% \mathrm{Cl} 95 \%$ confidence interval

Group A: controls; Group B: spontaneous clearance subjects; Group C: persistent infection patients. Group $(B+C)$ : HCV-infected individuals

aLogistic regression model, adjusted for gender, age and routes of infection Bold type indicates statistically significant results

hepatitis C virus, can inhibit $\mathrm{HCV}$ replication and mediate viral clearance, and disruptions by activated innate immune mechanism [9].

In our study, we found rs1535045 (located in intron1 of TNFRSF5) and rs1883832 (located in 5'UTR of TNFRSF5) have an association with susceptibility to $\mathrm{HCV}$ infection. However, no significant association was found among the three candidate SNPs and the spontaneous clearance of $\mathrm{HCV}$, which may be related to the smaller sample size included in the analysis. Therefore, this result should be further verified in large sample studies. These SNPs had been broadly researched in different genetic backgrounds. It turned out that rs 1535045 had connection to many diseases, such as coronary artery calcification [23] and small cell lung cancer [11], and rs1883832 was related to systemic lupus erythematosus [24] and acute coronary syndrome [25].

According to the bioinformatics information from UCSC, SNP rs1535045 was situated in highest peak of the H3k4me1, H3k4me3 and H3k27AC histone marker in 7 cell lines which were potential regulatory elements region (Fig. 1). We found rs1883832 was located at peak of transcription level assayed by RNAseq on 9 cell lines from ENCODE and H3k27AC histone marker in 7 cell lines (Fig. 1). Recent studies have found that probable pathogenic SNPs are enriched in the enhancer region and regulatory elements region, particularly in the H3K27Ac region, indicating that these mutations may have possible functions on gene transcription and expression process and then effect the disease susceptibility and outcomes [26, 27]. Besides, we identified whether these SNP could cause any differential expression of mRNA in different tissues by eQTL analysis. It turned out that different genotypes of rs1883832 could cause differential mRNA level of CD40 in whole blood $(P=$ $2.7 \times 10^{-9}$ ) (Fig. 2). Subjects carried the risk TT 


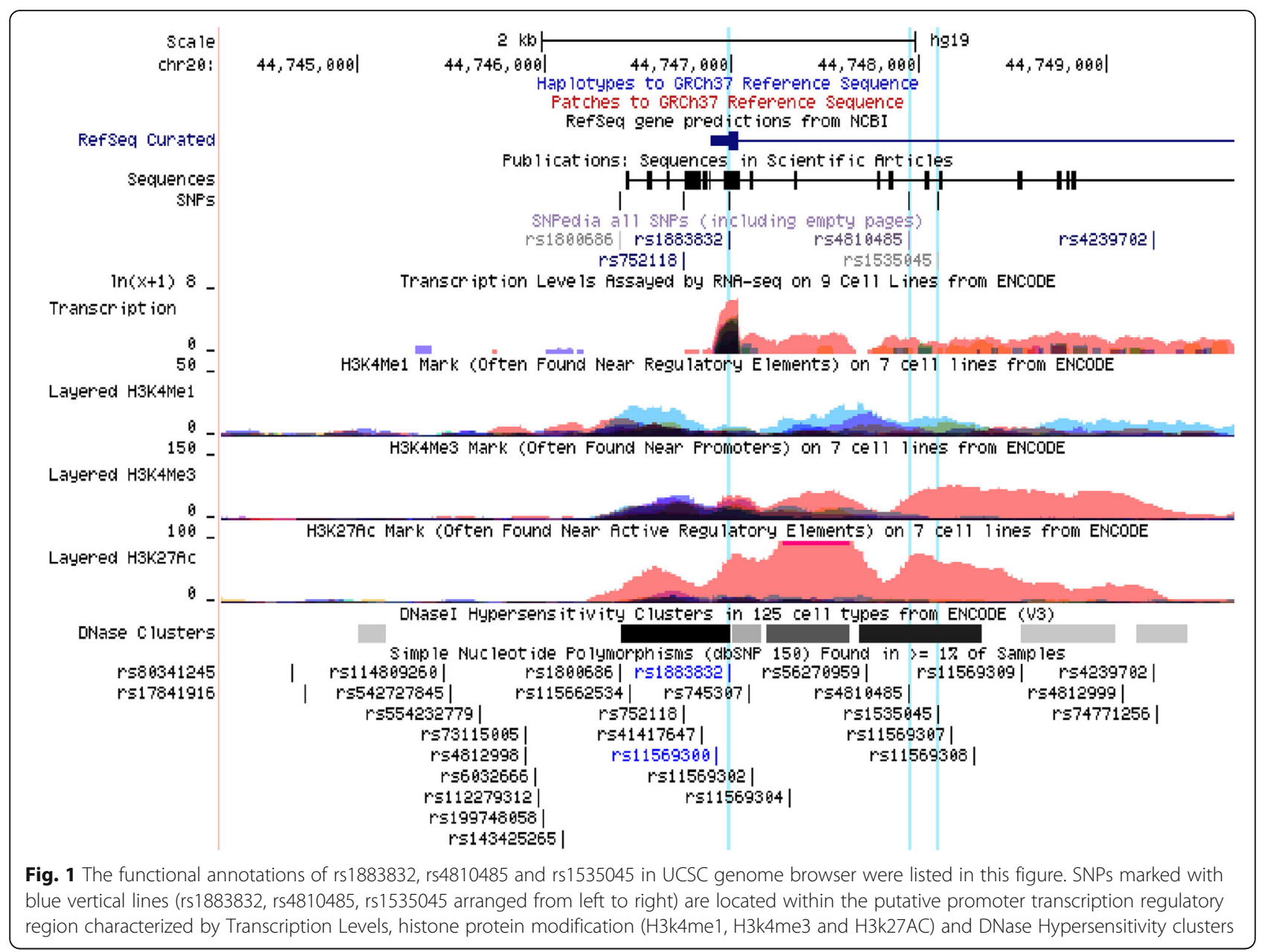

genotype had a lower CD40 mRNA levels, it was consistent with the results found by Rau SJ et al. that CD40 could inhibit HCV replication and mediate viral clearance, and disruptions [9].

In the stratified analysis, considering that the genetic pattern of positive SNPs is recessive, we conducted the analysis in recessive model. We found that rs 1535045 and rs1883832 significantly increased the risk of $\mathrm{HCV}$ infection in some subgroups. Although different gender and route of infection can bring complex infection environment and immune response, rs1535045 $\mathrm{T}$ allele and $\mathrm{rs} 1883832 \mathrm{~T}$ allele remained meaningful in various subgroups. In addition, the results of the cumulative effects and haplotype analyses showed a tendency of that the more risk alleles (rs1535045 T and rs1883832 $\mathrm{T})$ subjects carried, the more possibility of HCV infection exhibited.

This research did have some limitations. First of all, the samples included in this study were poorly representative and lacked important information that might affect the outcome, such as HCV genotype and IL28B genotyping results. Second, this is a cross-sectional study and the association should be better verified in cohort study. Third, the evidence based on bioinformatics analysis was obtained on the computer simulation, further functional experiment should be carried out. In addition, this study only included high-risk populations of $\mathrm{HCV}$ infection, which may overestimate the association between candidate SNPs and the susceptibility of HCV infection. Therefore, our results must be verified in larger cohorts in the future.

\section{Conclusion}

$C D 40$ polymorphisms was significantly associated with the susceptibility to $\mathrm{HCV}$ among Chinese populations. Further functional studies are needed to confirm the biological significance of these positive SNPs. This study provided the genetic evidence of association between CD40 polymorphisms and the outcome of 


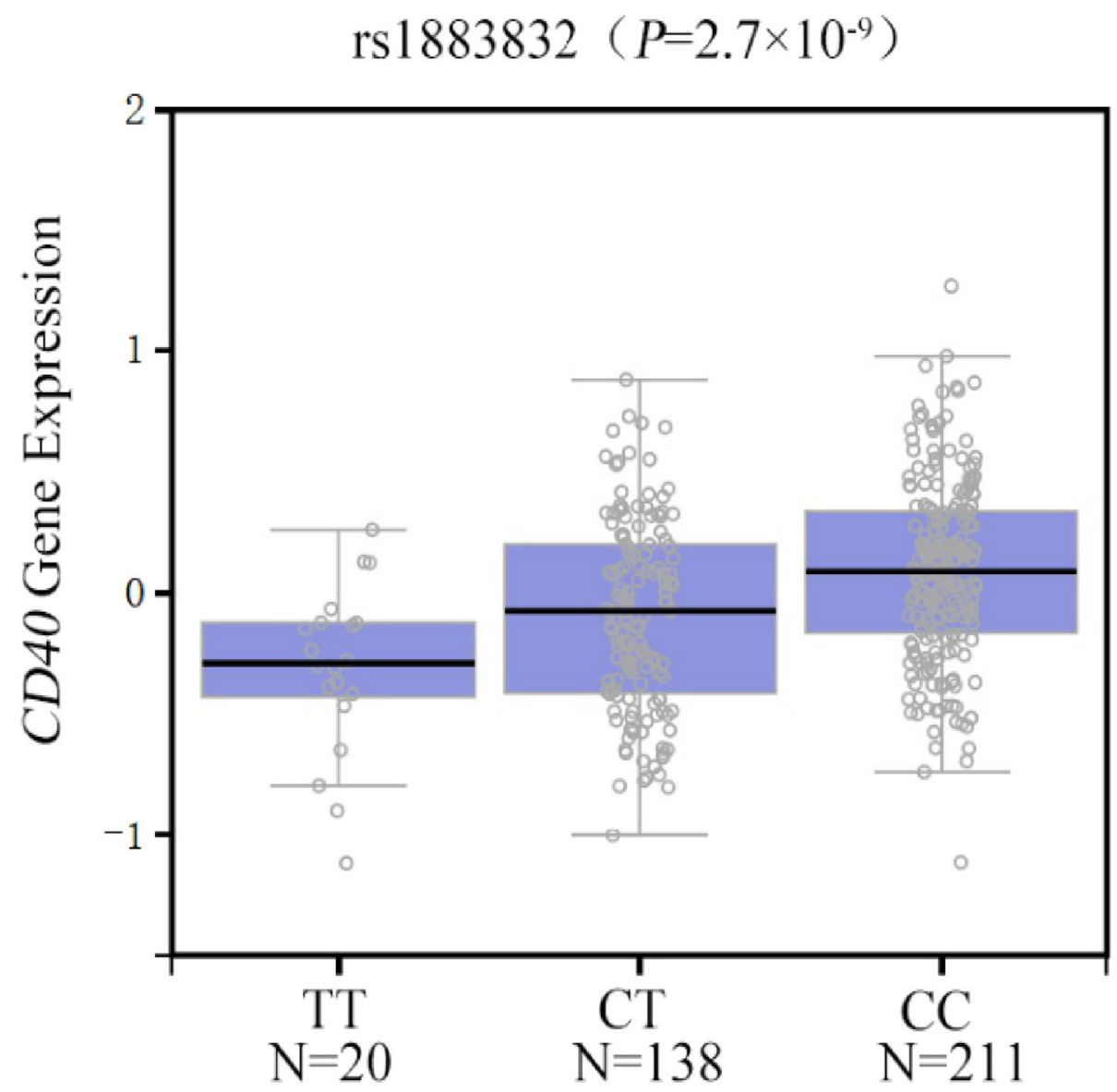

Fig. 2 Expression quantitative trait loci (eQTL) analysis of rs1883832 with CD40 mRNA expression levels in the whole blood samples. The results showed that minor T allele of rs 1883832 were pronouncedly associated with decreased expression levels of CD40. The $P$ values were derived from linear regression model. This data was obtained from Genotype-Tissue Expression project (GTEx V6p) Portal

$\mathrm{HCV}$ infection, and they may lead other scientists and clinician to identify new targets for therapy and personalized medical-based strategy by combined with other molecular genetics information.

\section{Supplementary information}

Supplementary information accompanies this paper at https://doi.org/10 1186/s12879-019-4482-5.

Additional file 1: Table S1. Probes and primers of investigated

TNFRSF5 SNPs for TaqMan assay.

\section{Abbreviations}

ALT: Alanine transaminase; AST: Aspartate aminotransferase; DAAs: Direct acting antivirals; eQTL: Expression Quantitative Trait Loci; HCV: Hepatitis C virus; LD: Linkage disequilibrium; MAF: Minor allele frequency;

TNFRSF5: Tumor necrosis factor receptor superfamily 5

\section{Acknowledgements}

The authors wish to thank Jie Wang, Yan Wang and Xiangyu Ye, for all the contributions to make this study carried out.

\section{Authors' contributions}

MY, PH participated in the design of the study. TT, HZF, JJW and ZQF carried out the surveys and experiments. MY, YZ, CHW, RBY and JL contributed to the acquisition and interpretation of data. TT, PH, XSX and CW performed the statistical analysis. TT and PH wrote the manuscript and Tables. MY prepared the figures. All authors read and approved the final manuscript.

\section{Funding}

This study was supported by the Natural Science Foundation of Jiangsu Province of China (grant numbers: BK20171054); the National Natural Science Foundation of China (grant numbers: 81773499, 81703273). "BK20171054" was used for the design of the study and collection. "81773499" and "BK20190106" was used for experimental consumables, analysis, and interpretation of data. "81703273" was used for writing the manuscript.

\section{Availability of data and materials}

The datasets used and/or analyzed during the current study are available from the corresponding author on reasonable request.

\section{Ethics approval and consent to participate}

This study was given permission by the medical ethics committee of Nanjing Medical University. All subjects had signed agreements on the informed consent materials to participate in this study.

Consent for publication

Not applicable. 


\section{Competing interests}

The authors declare that they have no competing interests.

\section{Author details}

'Department of Epidemiology and Biostatistics, Key Laboratory of Infectious Diseases, School of Public Health, Nanjing Medical University, Nanjing 211166, China. ${ }^{2}$ Jiangsu Provincial Center for Disease Control and Prevention Nanjing 210009, China. ${ }^{3}$ Chinese People's Liberation Army Eastern Theater Disease Prevention and Control Center, Nanjing 210002, China. ${ }^{4}$ Nanjing Drum Tower Hospital, Clinical College of Nanjing Medical University, Nanjing 210008, China. ${ }^{5}$ Faculty of Life Science and Technology, Kunming University of Science and Technology, Kunming 650500, China. ${ }^{6}$ Department of Infectious Diseases, the First Affiliated Hospital of Nanjing Medical University, No. 300 Guangzhou Road, Nanjing 210029, Jiangsu, China.

Received: 6 March 2019 Accepted: 16 September 2019

Published online: 15 October 2019

\section{References}

1. Thrift AP, El-Serag HB, Kanwal F. Global epidemiology and burden of HCV infection and HCV-related disease. Nat Rev Gastroenterol Hepatol. 2017; 14(2):122-32.

2. Shoukry NH, Hepatitis C. Vaccines, antibodies, and T cells. Front Immunol. 2018;9:1480

3. Horner $S M$, Gale M. Regulation of hepatic innate immunity by hepatitis C virus. Nat Med. 2013;19(7):879-88.

4. Duggal P, Thio CL, Wojcik GL, Goedert JJ, Mangia A, Latanich R, Kim AY, Lauer GM, Chung RT, Peters MG, Kirk GD, Mehta SH, Cox AL, Khakoo SI, Alric L, Cramp ME, Donfield SM, Edlin BR, Tobler LH, Busch MP, Alexander G, Rosen HR, Gao X, Abdel-Hamid M, Apps R, Carrington M, Thomas DL. Genome-wide association study of spontaneous resolution of hepatitis $C$ virus infection: data from multiple cohorts. Ann Intern Med. 2013:158:235-45.

5. Ge D, Fellay J, Thompson AJ, Simon JS, Shianna KV, Urban TJ, Heinzen EL, Qiu P, Bertelsen AH, Muir AJ, Sulkowski M, McHutchison JG, Goldstein DB. Genetic variation in IL28B predicts hepatitis C treatment-induced viral clearance. Nature. 2009:461:399-401.

6. Suppiah V, Moldovan M, Ahlenstiel G, Berg T, Weltman M, Abate ML, Bassendine M, Spengler U, Dore GJ, Powell E, Riordan S, Sheridan D, Smedile A, Fragomeli V, Müller T, Bahlo M, Stewart GJ, Booth DR, George J. $\mathrm{L} 28 \mathrm{~B}$ is associated with response to chronic hepatitis $\mathrm{C}$ interferon-alpha and ribavirin therapy. Nat Genet. 2009;41:1100-4.

7. Liu YJ, Joshua DE, Williams GT, Smith CA, Gordon J, MacLennan IC. Mechanism of antigen-driven selection in germinal centres. Nature. 1989; 342(6252):929-31.

8. Shiraki K, Sugimoto K, Okano H, Wagayama H, Fujikawa K, Yamanaka T, Ito T, Ohmori S, Sakai T, Takase K, Nakano T. CD40 expression in HCV-associated chronic liver diseases. Int J Mol Med. 2006;18(4):559-63.

9. Rau SJ, Hildt E, Himmelsbach K, Thimme R, Wakita T, Blum HE, Fischer R. CD40 inhibits replication of hepatitis $C$ virus in primary human hepatocytes by c-Jun $\mathrm{N}$ terminal kinase activation independent from the interferon pathway. Hepatology. 2013;57(1):23-36.

10. Chen JM, Guo J, Wei CD, Wang CF, Luo HC, Wei YS, Lan Y. The association of CD40 polymorphisms with CD40 serum levels and risk of systemic lupus erythematosus. BMC Genet. 2015;16:121.

11. Tang W, Xue L, Yan Q, Cai S, Bai Y, Lin L, Lin B, Huang M, Yi G, Li H. Association of Single Nucleotide Polymorphisms in the apoptosis-related genes TP63 and CD40 with risk for lung Cancer in a Chinese Han population. Tohoku J Exp Med. 2016:238(4):279-86.

12. Zhou L, Xie L, Zheng D, Li N, Zhu J, Wang S, Li B, Ye L. Genetic variants of CD40 gene are associated with coronary artery disease and blood lipid levels. Biomed Res Int. 2016;2016:1693619.

13. Liu ZL, Hu J, Xiao XF, Peng Y, Zhao SP, Xiao XZ, Yang MS. The CD40 rs1883832 polymorphism affects Sepsis susceptibility and sCD40L levels. Biomed Res Int. 2018;2018:7497314.

14. Lee YH, Bae SC, Choi SJ, Ji JD, Song GG. Associations between the functional CD40 rs4810485 G/T polymorphism and susceptibility to rheumatoid arthritis and systemic lupus erythematosus: a meta-analysis. Lupus. 2015;24:1177-83.

15. Grewal IS, Flavell RA. CD40 and CD154 in cell-mediated immunity. Annu Rev Immunol. 1998;16:111-35.
16. Alderson MR, Armitage RJ, Tough TW, Strockbine L, Fanslow WC, Spriggs MK. CD40 expression by human monocytes: regulation by cytokines and activation of monocytes by the ligand for CD40. J Exp Med. 1993:178(2):669-74.

17. Karmann K, Hughes CC, Schechner J, Fanslow WC, Pober JS. CD40 on human endothelial cells: inducibility by cytokines and functional regulation of adhesion molecule expression. Proc Natl Acad Sci U S A. 1995;92(10):4342-6

18. Kluth B, Hess S, Engelmann H, Schafnitzel S, Riethmüller G, Feucht HE Endothelial expression of CD40 in renal cell carcinoma. Cancer Res. 1997; 57(5):891-9.

19. Galy $\mathrm{AH}$, Spits $\mathrm{H}$. CD40 is functionally expressed on human thymic epithelial cells. J Immunol. 1992;149(3):775-82.

20. Sugimoto K, Shiraki K, Ito T, Fujikawa K, Takase K, Tameda Y, Moriyama M, Nakano T. Expression of functional CD40 in human hepatocellular carcinoma. Hepatology. 1999;30(4):920-6.

21. Hayden MS, Ghosh S. Regulation of NF-KB by TNF family cytokines. Semin Immunol. 2014;26(3):253-66.

22. Wang CY, Mayo MW, Korneluk RG, Goeddel DV, Baldwin AS. NF-kappaB antiapoptosis: induction of TRAF1 and TRAF2 and c-IAP1 and C-IAP2 to suppress caspase-8 activation. Science. 1998;281(5383):1680-3.

23. Burdon KP, Langefeld CD, Beck SR, Wagenknecht LE, Carr JJ, Rich SS, Freedman Bl, Herrington D, Bowden DW. Variants of the CD40 gene but not of the CD40L gene are associated with coronary artery calcification in the diabetes heart study (DHS). Am Heart J. 2006;151(3):706-11.

24. Joo YB, Park BL, Shin HD, Park SY, Kim I, Bae SC. Association of genetic polymorphisms in CD40 with susceptibility to SLE in the Korean population. Rheumatology (Oxford). 2013;52(4):623-30.

25. Wang M, Li Y, Li W, Xia ZE, Wu Q. The CD40 gene polymorphism rs1883832 is associated with risk of acute coronary syndrome in a Chinese case-contro study. DNA Cell Biol. 2011;30(3):173-8.

26. Farh KK, Marson A, Zhu J, Kleinewietfeld M, Housley WJ, Beik S, Shoresh N, Whitton H, Ryan RJ, Shishkin AA, Hatan M, Carrasco-Alfonso MJ, Mayer D, Luckey CJ, Patsopoulos NA, De Jager PL, Kuchroo VK, Epstein CB, Daly MJ, Hafler DA, Bernstein BE. Genetic and epigenetic fine mapping of causal autoimmune disease variants. Nature. 2015;518(7539):337-43.

27. Hnisz D, Abraham BJ, Lee TI, Lau A, Saint-André V, Sigova AA, Hoke HA, Young RA. Super-enhancers in the control of cell identity and disease. Cell. 2013;155(4):934-47.

\section{Publisher's Note}

Springer Nature remains neutral with regard to jurisdictional claims in published maps and institutional affiliations.

Ready to submit your research? Choose BMC and benefit from:

- fast, convenient online submission

- thorough peer review by experienced researchers in your field

- rapid publication on acceptance

- support for research data, including large and complex data types

- gold Open Access which fosters wider collaboration and increased citations

- maximum visibility for your research: over $100 \mathrm{M}$ website views per year

At BMC, research is always in progress.

Learn more biomedcentral.com/submissions 